\title{
The Journal Talks with 2011 TMS President Garry W. Warren
}

TMS President Garry W. Warren will complete his term as president of the society at the TMS 2012 Annual Meeting \& Exhibition this month. Warren, professor in the Department of Metallurgical and Materials Engineering, and Director of the Materials Science Program at the University of Alabama, Tuscaloosa, has long been involved in TMS activities. His involvement in TMS includes participation in the Extraction \& Processing Division, where he has served in numerous capacities. Warren has also served on the Programming Committee, the Financial Planning Committee, the Publications Coordinating Committee, and the TMS Board of Directors. As Warren neared the end of his term, JOM invited him to reminisce about the challenges and accomplishments of his year as president.

Q. Materials Innovation became a strong, new focus in 2011, particularly in light of the national Materials Genome Initiative announced in June. How do you see this initiative impacting future TMS activities?

A. Materials Innovation really covers a lot of territory. TMS has been involved in materials innovation for some time, but we didn't call it that. I view this initiative as an effort to accelerate the discovery, development, and deployment of materials systems and processes. These efforts can be illustrated, for example, by integrated computational materials engineering, and are strongly rooted in TMS programming and publishing activities. So, with this initiative, we're not doing something terribly different, but we're pulling it all together under the banner of Materials Innovation. I think this initiative, and the national Materials Genome Initiative to which Materials Innovation is connected, is very significant and holds great promise for the future. I recently visited a Material Advantage chapter and told the students that this is the first time I can remember in my lifetime when leaders in government and industry were talking about and focusing specifically on materials. The students were very enthusiastic about the implications for their profession.

Q. The TMS Foundation was the subject of much discussion and interest in 2011. What changes are in store for the Foundation as a result?

A. Our first priority is to grow the Foundation so we can do more to impact TMS, and society, in several different ways. Supporting the young, up-and-coming members of our society is important; they are the future - the lifeblood - of TMS. The scholarships funded by the Foundation encourage the next generation of materials scientists and engineers to continue their academic pursuits. Through the Young Leaders program we nurture the future committee chairs, symposium organizers, and Board members of our society, for example. Also for young professionals, the Foundation has endowed the Vittorio de Nora Prize for Environmental Improvements in Metallurgical Industries - a significant prize that benefits young practitioners. The Foundation can help keep new blood flowing into our key activities, building our future with strong lines of succession.

The Foundation is also a strong sup- porter of the Materials and Society Committee and its activities. As an academic, I'm excited about the committee. I'm hopeful and optimistic that the Foundation will help us to showcase what we do as materials scientists and engineers, and how it affects and benefits society. We, in the past, have supported Engineers without Borders activities in Mali, Africa. In addition, I'd love to see the Foundation be able to support, through funding or prizes, innovative senior design projects at universalities that showcase to society at large, especially younger students, the nature and importance of metallurgical and materials engineering.

To maintain all these valuable programs and to build upon them, we must increase the funding pool available to the Foundation. Members will see an increased visibility of this group at the TMS 2012 Annual Meeting \& Exhibition, where the TMS Foundation will host a booth and offer some enticing incentives for donations.

More activity is planned over coming years to enhance the role of the Foundation in supporting TMS, and society at large. Stay tuned, but don't wait to donate!

Q. The board tackled strategic planning this year. What were the key outcomes and how do you see those discussions affecting TMS members?

A. This strategic planning, to chart the course of TMS through 2015, is a work in progress. Discussions began at Materials Science \& Technology 2011 and have continued into 2012. Although details are still being developed, areas where we can expect to see more activity include nurturing our young 
professional members; supporting the volunteer structure that is essential to the society's success; growing core technology areas that are fundamental to TMS as a "Minerals, Metals \& Materials" society; continue to focus on materials solutions for energy challenges; and continue to emphasize materials and manufacturing innovation in our programming and advocacy pursuits.

Although many of these activities represent expansions of ongoing initiatives at TMS, the emphasis on advocacy is an emerging priority. Speaking to congressmen, senators, their staff, and other governmental officials, informing them of the relevance and importance of what we do, is critical to our profession. The Materials Genome Initiative will not progress rapidly or efficiently unless decision makers who hold the purse strings understand how innovation in materials design and processing can translate into huge efficiency improvements in manufacturing and to the development of entirely new products.

Q. TMS has always worked to strike a balance by nurturing its core while looking to the future. Have there been activities or initiatives in the past year that speak to nurturing the core?

A. The Materials Genome Initiative does that in spades. It's beginning to tie up a whole lot of loose ends, as I see it. Our field is very diverse, with people who work on processing: mashing, bashing, thrashing, and melting... whatever you do to produce materials. Then there's a whole lot of other people doing computer modeling, other people using entirely new tools to perform characterization that was never possible until now. Just in the past decade, for some materials and products, we have successfully knitted together these disparate pieces into a whole fabric that has simultaneously cut years off the traditional development time, saving millions of dollars in time and energy costs.

Q. What TMS initiative or activity gave you the greatest satisfaction during your tenure as President?

A. Getting to know and appreciate the staff more has been very satisfying. In a different vein, the groundwork we laid for the Foundation's growth has been especially rewarding. We need significant growth in the Foundation, for which I see a positive future as a result of the planning and goal-setting that began this year.

\section{Q. What has been the biggest challenge of your term?}

A. My term as president has been both challenging and rewarding. It's required perhaps a little more time than I had imagined to keep up on the reading, attend various meetings, and travel. On the other hand, I never found it boring. Quite the opposite, it was fun.

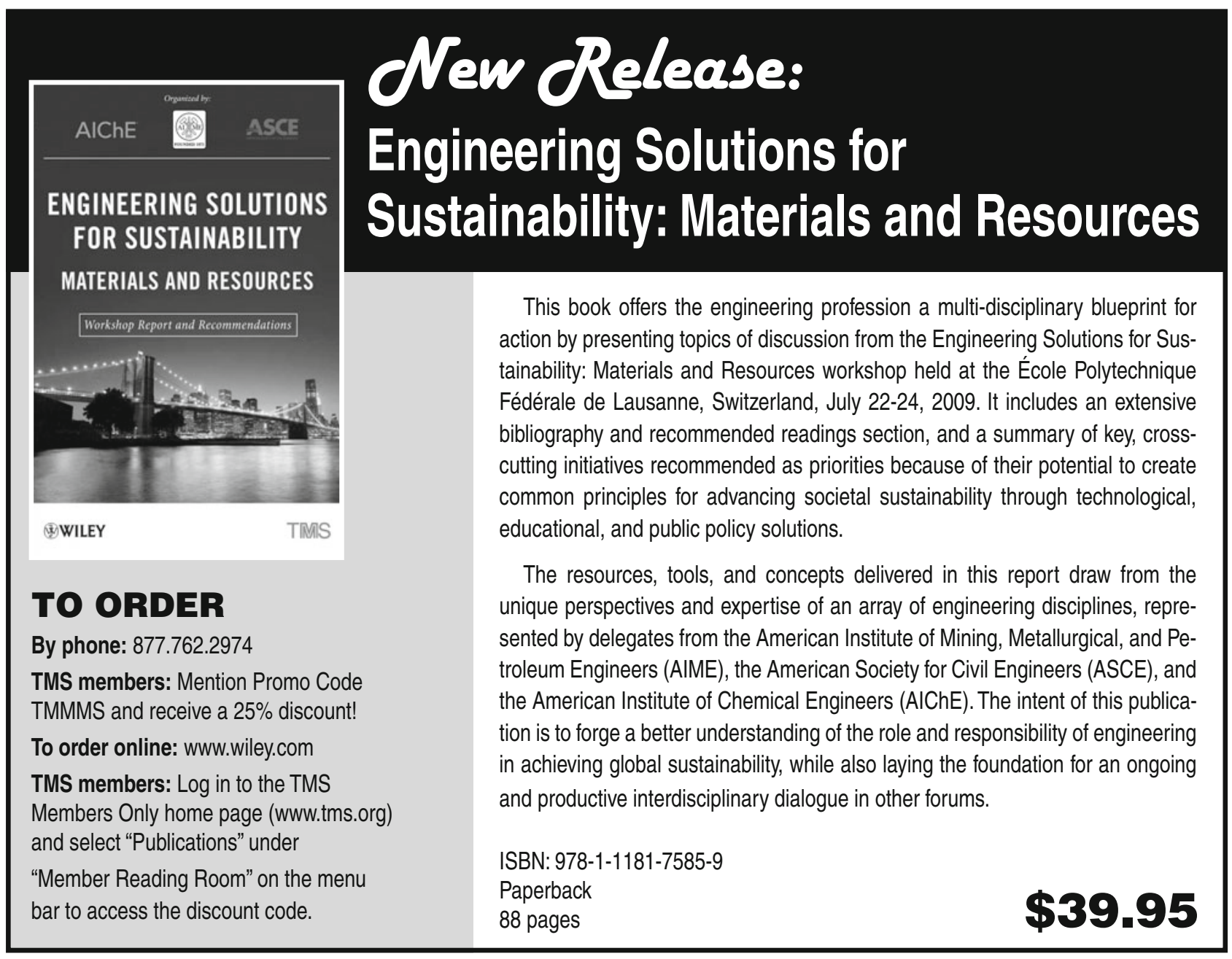

